\title{
Supporting and Mentoring New Social Work Instructors: A Formative Evaluation of the TEAM Program
}

\author{
Shane R. Brady, PhD, MSSW \\ University of Oklahoma \\ Michael S. Spencer, PhD, MSSW \\ University of Washington
}

Abstract: This study provides formative evaluation results from a pilot peer mentorship and teaching support program designed, implemented, and evaluated at a school of social work located in a major Midwestern Carnegie research I (RI) university over a 3-year span. Through utilizing an adult learning approach, the Teaching Excellence and Academic Mentorship (TEAM) program was created as a way to foster community among first-time instructors at the school in order to promote peer support and mentorship in the classroom. The qualitative results of this study indicate agreement among new instructors that peer support and mentorship were helpful during their first year of teaching at the school. Additionally, results point to new instructor concerns about creating a culture for teaching at an RI institution, faculty buy-in or commitment to mentorship, and long-term options for continued mentorship and support in the classroom beyond their first year.

Keywords: teaching mentorship, higher education, social work education, teaching communities.

The challenges associated with first year teaching are well known by faculty and administrators of colleges and universities. Little has been written about what is being done by institutions of higher education to help strengthen the capacity of new instructors to succeed in the classroom, especially at RI institutions that often prioritize research over teaching outcomes (Richardson, 1992; St. Claire, 1994). During the past decade, the percentage of courses taught by part-time faculty and graduate students has increased $40-65 \%$ across institutions of higher education (Boyle \& Boice, 1998; Richardson, 1992; Savage, Karp, \& Logue, 2004). The steady increase and demand for qualified part-time instructors and graduate teaching assistants has led to a renewed interest in new instructor preparation and mentorship (Gaia, Corts, Tatum, \& Allen, 2010). While part-time instructors and graduate students often hold increased responsibilities for teaching courses at many schools across the country, teaching is also a requirement and expectation for most new tenure track and tenured faculty as well.

Although new faculty are expected to teach anywhere between 1-4 courses a semester, depending on the institution, many have very little, if any, experience teaching in higher education, particularly at the graduate level (Sands, Parson, \& Duane, 1991; Thomas, 2005). While some new faculty members may have taught or co-taught courses during their doctoral or graduate programs, those who attended research-intensive doctoral programs were likely only mentored by experienced faculty in research, not in teaching (Boyle \& Boice, 1998; Gaia, Corts, Tatum, \& Allen, 2010). One way that programs and institutions are addressing the needs of new instructors is through the development of peer mentorship programs and intentional teaching communities (Schonwetter, \& Nazarko, 2009). Mentorship programs provide support to new instructors in many different ways, however, in a survey conducted by Ohio State University on 
instructors' perception of mentorship, only 33.3\% of instructors across instructional levels stated that they were mentored during their time as an instructor (Sands, Parson, \& Duane, 1991). Mentorship programs provide new instructors with necessary connections for meeting other faculty and staff, receiving feedback on teaching, social support, and knowledge about informal norms or rules (Popper, 2007; Savage, Karp, \& Logue, 2004; St. Claire, 1994).

New instructors in the school of social work where this article is based, experienced most of the challenges described in the literature, which over time, led to modest declines in student evaluation scores of new instructors, lower retention rates among part-time instructors, and increased student complaints made to administration about the performance of new instructors. As a result of these challenges, the Teaching Excellence and Academic Mentorship (TEAM) pilot program was created through collaboration between an administrator and part-time instructor at the school. TEAM was designed to provide resources, support, and peer mentorship to new instructors at the school during their first year, regardless of whether they were faculty, part-time instructors, or doctoral students. Another purpose of the program was to build an intentional teaching-centric community among new instructors, which would eventually begin to draw in participation from experienced faculty and instructors. The evaluation hypothesis behind TEAM was that if the school supported new instructors in teaching and getting acclimated to the school and university, it would help to improve the quality of teaching in the classroom, increase retention rates among part-time instructors, and build a more supportive culture for teaching in the school. As part of the overall evaluation of TEAM, qualitative data was collected over the course of 3 years from regular check-in meetings and end of the year reflection sessions. The purpose of the qualitative portion of the evaluation was to gather data about the specific benefits and gaps within the current program in order to improve it in the future. Another purpose behind the check-in meetings and end of the year reflection sessions was to better understand the experiences and needs of new instructors. The qualitative results from the first 3 years of the TEAM program are shared in this paper for the purpose of modestly helping to inform other schools and programs interested in helping support the teaching of new instructors more effectively.

\section{Literature Review}

The literature on the benefits of mentorship in higher education is plentiful (Savage, Karp, \& Logue, 2004). Mentorship, however, is defined very broadly throughout the literature of higher education and social work education (Savage, Karp, \& Logue, 2004). Mentorship in higher education is best paraphrased in the literature broadly as formal and informal processes, activities and initiatives aimed at supporting faculty and staff in professional development (Gaia, Corts, Tatum, \& Allen, 2010). The activities and supports provided through mentorship programs in higher education often overlap with institutional support programs but differ in that mentorship programs usually involve building supportive relationships between faculty and staff to promote professional learning and growth (Hudson, P. Hudson, S. Gray, \& Bloxham, 2013). Some of these supports include; new instructor orientations, faculty development trainings, appointed mentors, and peer mentorship communities of support (Boyle \& Boice, 1998; Sands, Parson, \& Duane, 1991). Successful mentorship programs often lead to; higher retention rates for part-time instructors, better student learning experiences, more confident instructors, better-prepared future faculty, and a greater sense of connectedness and community among faculty and staff (Luna \& Cullen, 1995; Popper, 2007).

Journal of the Scholarship of Teaching and Learning, Vol. 18, No. 2, June 2018. josotl.indiana.edu 


\section{Approaches to Mentorship}

Two major approaches to mentorship program structures primarily exist in the literature. The first type of mentorship program is the formal mentorship program, which is generally characterized by increased structure, institutional buy-in, formal activities, sometimes mandates to participation, and are often tied to assessment and evaluation of instructor performance in the classroom. The second type of mentorship program is less formal and voluntary in nature. Voluntary mentorship programs are often peer initiated and facilitated, are more centered on the individual learning needs of instructors, receive very little formal support from institutions, and tend to emphasize building intentional supportive relationships among peer instructors, rather than focus primarily on improving instructors' teaching (Heńard \& Roseveare, 2012; Kalish, 1997; Gross \& Stovall, 1994; Savage, Karp, \& Logue, 2004).

While formal programs provide a consistent message, curriculum, and skill development to new instructors, these programs are often critiqued by instructors as not being flexible enough to take into account the unique and emerging individual needs of instructors (Sands, Parson, \& Duane, 1991; Ebersole, 2003). Mentorship that occurs more informally allows for the emergence of instructor needs, but may not always meet the needs of new instructors as a result of being dependent upon new instructors self-identifying and voicing their needs as well as experienced instructors making the time and putting forth the effort to provide support (Cox, 2004; Gross \& Stovall, 1994; Schonwetter \& Nazarko, 2009). While an informal mentorship program, may on the surface, seem like the more attractive structure for promoting community and teaching excellence among new instructors, it is important to consider deeper level concerns about the accessibility of mentorship to new instructors. Although many institutions, schools, and departments claim to support and encourage mentorship, including most schools of social work, often it is done through informal mechanisms. The major drawbacks of not formalizing mentorship, however, is that women and minorities often experience isolation from existing faculty and may not feel comfortable reaching out due to concerns over institutional racism, sexism, and power dynamics (Sowers-Hoag \& Harrison, 1991; Simon, Bowles, King, \& Roff, 2004). It is also true that many new instructors are readily aware of the hierarchy of power that exists in most institutions between non-tenured and tenured faculty and as a result may not feel comfortable being vulnerable to colleagues who could have decision-making power over their professional trajectory at some point (Wilson, Valentine, \& Periera, 2002).

Finally, new instructors may not always realize the benefits of mentorship, unless they had positive experiences with mentoring relationships in the past (Savage, Karp, \& Logue, 2004). It is also true that many new instructors across levels routinely underestimate how difficult teaching can be, especially in a new institutional setting, thus making it imperative that formal mechanisms are established by the institution to support the mentorship program (Wasserstein, Quistberg, \& Shea, 2007). While it may be difficult in current economic times to secure funding for the support of more formal teaching mentorship programs, small scale changes and improvements can go a long way in establishing a culture of support and teaching excellence in higher education. This is particularly the case when there is buy-in and commitment to supporting mentorship from administration and instructors alike (Klein, Weisman, \& Smith, 1996; Wilson, Valentine, \& Periera, 2002).

Journal of the Scholarship of Teaching and Learning, Vol. 18, No. 2, June 2018.

josotl.indiana.edu 
In addition to understanding the typical structures for successful teaching mentorship programs, another consideration that many institutions and administrators must contemplate is the extensive and varying needs of new instructors across ranks or categories.

Graduate student instructors. Doctoral students play an important role in the future and present of social work research and education. Doctoral programs typically cast doctoral students into one of two distinct roles; graduate research assistants or graduate student instructors (Gonzalez, 2001). It is often difficult to determine by merely looking at a school of social work's ranking or prestige as to which model they follow with graduate students. Often larger programs with strong research interests may utilize doctoral students to assist faculty conducting extensive research projects, both as a source of much-needed labor for faculty and as part of the curriculum and/or funding package provided to graduate student (Gaia, Corts, Tatum, \& Allen, 2010). At other times, schools may depend on graduate students to teach foundation courses in order to help alleviate the teaching burden of tenured and tenure-line faculty members, who often have intensive research, committee service, advising, and other requirements placed upon them (Gonzalez, 2001).

Graduate and doctoral programs that utilize teaching assistants provide various levels of mentorship and support to students (Gaia, Corts, Tatum, \& Allen, 2010; Wasserstein, Quistberg, \& Shea, 2007). Most doctoral programs provide some form of orientation to student instructors, which usually consist of a minimum of content related to institutional policies, grading, basic technology, and expectations. Additionally, some schools provide increased content related to developing and implementing curriculum, teaching philosophy, classroom management training, and addressing sensitive topics and conflict in the classroom (Boyle \& Boice, 1998). Lastly, what is known about the teaching preparedness and mentorship of doctoral students is that while many schools and programs are doing something to orientate and support doctoral students in classroom teaching, there are wide variations in what is being done (Gonzalez, 2001). Often doctoral students are mentored in research and scholarship, but not directly in the area of teaching (Boyle \& Boice, 1998; Popper, 2007). Additionally, while some program directors and faculty are writing formally about the positive outcomes and challenges of preparing and mentoring doctoral students for classroom success, many are not publishing beyond an institutional level (Savage, Karp, \& Logue, 2004).

New faculty members. The next largest group that schools of social work, and many others, are investing resources in is new faculty members. New faculty members provide fresh perspectives, current best practices, and technological innovations that are beneficial to programs and institutions (Luna \& Cullen, 1995). New faculty members generally receive some formal orientation process at the university and/or department level. The focus of orientation is to familiarize faculty to their new surrounding and the organizational culture and formal policies of their employer institutions (St. Claire, 1994). Some departments, schools, and programs have developed concrete supports for new faculty members, which may include pairing them with a senior faculty member, providing them with small research incubation grants, and focusing on what it takes to meet tenure demands (Boyle \& Boice, 1998; Cameron \& Blackburn, 1981).

Although many schools evaluate teaching, research, service, and sometimes fund development in some form when determining tenure and promotion of faculty members, more focus in recent years has been placed on research and fund development, especially at RI institutions (Popper, 2007). While the literature also states that some emphasis on teaching preparedness and support is provided to new faculty members, most of the emphasis for teaching specific support takes place at community college and teaching centered institutions and

Journal of the Scholarship of Teaching and Learning, Vol. 18, No. 2, June 2018. josotl.indiana.edu 
programs (Sands, Parson, \& Duane, 1991). The lack of formal literature, especially in social work, about what is being done to promote and encourage teaching excellence among new faculty members, especially those at RI institutions, presents a gap in the knowledge base of higher education.

Part-time faculty. By far, the group of new instructors that are at the greatest deficit for mentorship and support are adjunct faculty or part-time instructors. Almost all institutions utilize part-time instructors to fill the instructional needs of institutions (Friedlander, 1980; Hénard, \& Roseveare, 2002). Part-time faculty are especially relevant to social work, nursing, and teaching programs, where real world expertise and experience is needed in curriculum and practicumbased courses (Richardson, 1992). Part-time faculty currently teach anywhere from 40-70\% of the teaching load at many schools, with community colleges generally reporting higher proportions of courses taught by part-time instructors than four-year colleges and universities (Richardson, 1992; Savage, Karp, \& Logue, 2004). Although community colleges may utilize part-time instructors in higher proportions than four-year institutions, according to the American Association of University Professors (AAUP), more than $51 \%$ of university teaching is now being handled by part-time or adjunct instructors (AAUP, 2015).

Although part-time instructors play an important role in teaching the next generation of professionals, they receive the least amount of attention in the literature and are given the fewest supports and resources at most institutions (Schonwetter \& Nazarko, 2009). Part-time instructors in social work are typically practicing or recently retired practitioners that are seeking an opportunity to give back to the profession (Klein, Weisman, \& Smith, 1996). While many parttime instructors teaching for the first time have extensive professional practice experience, they have little teaching preparedness or experience in academic environments (Fagan-Wilen, Springer, Ambrosino, \& White, 2006; Klein, Weisman, \& Smith, 1996). There is not a great deal of discussion in the literature of higher education about the rationale for not providing better support to part-time instructors in the classroom through mentorship; however, it has been suggested by some that funding cuts, tighter budgets, and increased focus on funded research may contribute to the lack of investment in the development of part-time faculty (AAUP, 2015; Schonwetter, \& Nazarko, 2009).

It is the result of the many challenges faced by all categories of new instructors illustrated in the literature, and experienced firsthand by the authors, which led to the creation of the Teaching Excellence and Academic Mentorship program (TEAM) to support new instructors across ranks and levels during their first year of teaching in the school.

\section{Program Overview}

The TEAM program was designed to provide increased teaching specific support and mentorship to first-year instructors at the school. The first step to improving institutional support to new instructors was achieved by creating a comprehensive six-hour orientation program. The orientation consisted of content and exercises specific to teaching, as well as activities meant to build community among new instructors. Guest speakers from inside the school and university were brought in to help new instructors better understand university technology systems, library resources, human resources, and existing teaching supports. Student panels were also included in the orientation sessions to help new instructors understand student perceptions about quality teaching and instructors. 
An additional critical component of the TEAM program was the utilization of a peer facilitator as a mentor to new instructors. The peer facilitator, also referred to as the peer mentor, was a part-time instructor with stellar teaching evaluations, experience, and additional training specific to teaching in higher education. The peer facilitator was readily available and accessible to new instructors throughout their first year, and helped coordinate and co-lead regular check-in meetings, while also working to connect new instructors with other quality instructors in the school for long-term mentorship opportunities. Another component of TEAM was the utilization of regular check-in meetings at the beginning, midway point, and end of the year. The check-in meetings were held each semester as a means for processing, learning, and troubleshooting potential issues new instructors were experiencing. An adult education approach was utilized to facilitate the meetings, which meant the facilitator simply helped frame the meetings and asked questions of the instructors, but instructors dialogued with one another about issues and challenges in order to find practical solutions for addressing them. Meetings were strategically held at the beginning, mid-way point, and end of the semesters so that multiple opportunities were provided for mutual learning. The final check-in meeting was facilitated as a reflection session with more semi-structured questions related to new instructor challenges and the benefits and deficits of the TEAM program.

\section{Participant Description}

The program sample frame included 20 new instructors who utilized at least some portion of the TEAM program and attended at least $50 \%$ of program activities during their first year of teaching. The first year of the program included six new instructors, while years 2 and 3 included seven new instructors per year. In general, new instructors taught at least one course in each semester of their first year at the school and participated in the program during the fall and winter semesters. The demographic characteristics of participants were that $35 \%$ identified as male and 65\% female, race/ethnicity demographics were not included due to low response rates for answering this question. Approximately $70 \%$ of TEAM participants had some prior teaching experience at another institution or program, often at an undergraduate level, while $30 \%$ of participants indicated no prior teaching experience. All instructors involved had no prior teaching experience at the institution that served as the setting for the TEAM program.

The demographics and characteristics of new instructors are considered typical based on the composition of new instructors in previous years. The categorization of TEAM participants by instructor level was identified as the most important characteristic for tracking purposes, due to the emphasis in the literature on the differing needs of adjuncts, graduate students, and junior faculty. Eight participants of TEAM were new adjunct faculty, eight were doctoral students, and four were new faculty members. While these groups could not be separated during the program, since the program was designed to provide support to all new instructors regardless of rank or category, during the final analysis, groups were separated by category to understand the unique needs and perspectives of each category of new instructors.

\section{Program Approach and Evaluation Framework}

Given the action-oriented nature of teaching and learning the authors utilized an action learning and research approach in the development and implementation of the mentorship program. The action learning approach has theoretical roots in the work and ideas of Brazilian educator Paulo

Journal of the Scholarship of Teaching and Learning, Vol. 18, No. 2, June 2018. josotl.indiana.edu 
Freire (1970) and more recent work of adult education researcher Elizabeth Lange (2004), both view action learning as an emergent and evaluative process for dialogical learning and reflection involving adult learners in educational and community settings. Action learning emphasizes; dialogical learning in small groups, the use of a facilitator instead of a leader, engagement in praxis (critical reflection), and putting into practice knowledge gained from reflective learning(Lange 2004; Freire 1970). The principles of action learning emphasizes co-learning as a more effective method for adult learners than traditional educational approaches which emphasize leadership, the hierarchy between teachers and learners, and the notion that the teacher or leader has greater expertise than the students in the classroom or group (Freire, 1970). Furthermore, action learning was chosen as an approach for facilitating and evaluating the TEAM program as a means to aid support and mentorship among peers. Due to the inherent challenges of recruiting experienced instructors for teaching specific mentorship and the hierarchy that often exists in RI schools where tenured faculty are often considered more powerful than tenure-track or non-tenured instructors (Giroux, 2009).

For the purpose of evaluating the TEAM program participant experiences and identified needs was a major focus for the purpose of formative evaluation. As a result of the formative focus of this evaluation, qualitative methods were utilized in order to better understand the strengths and challenges of the program as well as the experiences of new instructors. Data were collected over the course of three years. Data were collected primarily through detailed notes taken from 18 meetings that were held with new instructors, three per semester. While the first two sessions each semester, one at the beginning of the term and one at the midway point of the term, were facilitated as loosely structured check-in meetings and were approximately 60-90 minutes in length, the final end of the semester meeting was framed as a reflection session. The reflection sessions were 2 hours in length and included more semi-structured questions posed by the facilitator for the purpose of better understanding how new instructors experienced teaching, the TEAM program, and the school as a whole during their first year. The utilization of dialogical conversations, along with more semi-structured conversations, provided a suitable and balanced data collection protocol that has precedence in the development of adult education programs (Stringer, 2014). Notes for these sessions were taken by the facilitator and by a graduate student volunteer. While names were not recorded, the instructor category of each member (new faculty, adjunct, doctoral student) was documented in order to better compare responses between groups.

\section{Data Analysis}

For the purpose of analyzing qualitative data collected during the formative evaluation of the TEAM program, the framework of Strauss and Corbin (1998) and Bazeley (2009) were consulted for guidance. Given the formative goals of TEAM, qualitative data were collected as a means to understand the strengths and challenges of the pilot program, as well as provide additional data about the overall needs of new instructors. Qualitative data collected through check-in meeting and reflection session notes were initially coded along 3 major categories: needs of new instructors, strengths of the program, and areas for improvement. The program facilitator and another university researcher conducted coding separately, and an initial agreement was reached on $90 \%$ of the codes. The facilitator and researcher discussed all codes where agreement was not reached until consensus toward sorting of data and labeling of codes could be attained. All final codes were verified with new instructors for accuracy, and changes

Journal of the Scholarship of Teaching and Learning, Vol. 18, No. 2, June 2018. josotl.indiana.edu 
were made based on the consensus of feedback provided by new instructors. In this study, final codes were placed into two major categories related to the formative evaluation of the program: strengths and weaknesses. Codes were included if 50\% or more of participants identified and/or agreed with the strength or weakness during the check-in and reflection sessions. Themes are represented as larger level challenges or needs experienced by new instructors, and are reported in table 3 of the subsequent results section of this paper.

\section{Results}

Table one below illustrates program strengths identified by new instructors who participated in the TEAM program:

\section{Table 1. Mentorship Program Strengths Identified by New Instructors}

\begin{tabular}{ll}
\hline Instructor Type & Program Strengths \\
\hline Part-time professors & $* *$ Peer Mentor (Facilitator) \\
& $* *$ Orientation \\
& $* *$ One-on-one consult \\
& Help connecting with other instructors \\
& Virtual resource site \\
& **Peer Mentor (Facilitator) \\
Doctoral students $(\mathrm{N}=8)$ & $* *$ One-on-one consult \\
& Help connecting with other instructors \\
& Orientation \\
& $* *$ Go-to-Person (Facilitator) \\
& $* *$ Virtual resource site \\
New faculty $(\mathrm{N}=4)$ & Help connecting with other instructors \\
& Orientation \\
\hline
\end{tabular}

** Denotes at least 75\% agreement among new instructors within the category

Table one above indicates that the strengths of TEAM as identified by new instructors were similar across all categories of new instructors. By far the greatest asset of the TEAM program was having a go-to person for beginning mentorship needs, help, and direction. New instructors stated that it could be challenging to enter a new position and not know anyone or be faced with having to e-mail administrators or support staff over and over again. Through providing new instructors with someone who was knowledgeable with the university and school systems, who also taught at the school, new instructors felt less stressed and more welcomed into the school. Another asset of the TEAM program was orientation, which prior to TEAM had not formally existed at the school. Previously, new faculty/instructors to the school would meet with human resources and support staff about courses, and the administration would send them course outline exemplars or 'master syllabi' to aide them in creating their courses. The TEAM program created a new 6-hour orientation program for new instructors that covered a broad range of relevant topics and promoted community building among new instructors. While new part-time instructors found the orientation to be beneficial, doctoral students and new faculty found it less helpful. Doctoral students indicated that much of the information provided at orientation did not 
apply to them, as they already knew much of the information from being students. New faculty members indicated that the orientation was too long and did not cover topics beyond teaching that applied to their position.

Another asset of TEAM was one-on-one consulting with new instructors. While TEAM provided a mentor to help new instructors navigate the university system and to answer questions, the consulting feature of the program was designed for those instructors wanting more direct help with teaching, curriculum development, activities, rubrics, and course management software. The consult feature of TEAM was most appreciated by new part-time instructors and doctoral students, while new professors chose not to utilize this resource as much, but agreed that it was a worthwhile feature for new instructors.

One of the major aims of TEAM was to facilitate mentoring relationships and community among new instructors, and also connect new instructors to other instructors in the school in order to build supportive relationships and networks for new instructors that would last after the TEAM program. While all new instructors mentioned having made some connections with instructors and staff at the school as a result of participating in the TEAM program, there was quite a bit of variance in the quality and productivity of the relationships made with faculty and staff.

Finally, one of the assets deemed beneficial to some new instructors was the help provided in setting up virtual course sites. While doctoral students stated that they did not utilize TEAM for technology support, given that they were already familiar with the platform from being students, new faculty members indicated this feature of the TEAM program as being very helpful, as it reduced frustration and ensured prompt accessibility to online systems upon hire.

Table 2. Mentorship Program Challenges Identified by New Instructors

\begin{tabular}{ll}
\hline Professor Type & Program Deficits \\
\hline Part-time professors $(\mathrm{N}=8)$ & $\begin{array}{l}* * \text { Check-in meeting scheduling } \\
* * \text { No formal support beyond first year } \\
* * \text { Lack of faculty buy-in and support }\end{array}$ \\
& $\begin{array}{l}* * \text { Lack of faculty buy-in and support } \\
\text { Doctoral students }(\mathrm{N}=8)\end{array}$ \\
& Check-in meeting scheduling \\
New faculty $(\mathrm{N}=4)$ & $* *$ Orientation too long and poorly timed \\
& $* *$ Faculty have different pressures and needs beyond \\
& teaching \\
& $* *$ Check-in meeting timing at busy times \\
& Lack of faculty mentors
\end{tabular}

** Denotes at least 75\% agreement among new instructors within the category

While the TEAM program experienced many successes over the three-year pilot program, new instructors also identified several deficits with the program. The deficits identified by new instructors were directly related to the components of the program that new instructors most utilized, which varied by category. For instance, check-in meetings were identified as problematic by all new instructors' due to the scheduling of meetings. This challenge was likely due to the very different schedules maintained by all three new instructor categories. While parttime instructors often worked a full-time job during the day, making it difficult to attend check-in 
meetings held during the day, doctoral students and faculty preferred to hold check-in meetings during the normal working day, when they are already at the school.

Another major challenge identified by new instructors related to finding mentorship and support outside the TEAM program among other faculty and staff. While some new instructors easily made connections and had begun forging relationships with other instructors and faculty in the school, many found it difficult to make relationships with faculty and other instructors. Some new instructors stated that teaching did not seem to be of interest to others in the school, and most people were not knowledgeable about the TEAM program, so they did not understand the purpose and aims. Other deficits related to TEAM varied across categories of new instructors. New part-time instructors expressed a strong desire for TEAM to support instructors past their first year, while doctoral students felt like TEAM should provide more teaching workshops for students new to the profession. Finally, while new faculty members widely supported the TEAM program, they felt as though it was not geared towards new faculty members with positions that emphasized research and/or grant writing. Overall, the deficits identified by TEAM participants provide room for the program to improve and grow in the future.

\section{Table 3. Institutional Barriers to Teaching Identified by New Instructors}

\begin{tabular}{ll}
\hline Professor Type & Unmet Institutional Needs Identified by New Instructors \\
\hline Part-time professors & $* *$ More community in the school \\
$(\mathrm{N}=8)$ & $* *$ Shift in culture towards teaching \\
& $* *$ Better work spaces with privacy \\
& Support from admin in student/grade conflicts \\
& Free parking \\
& Part-time instructor feedback in curriculum \\
& \\
Doctoral students $(\mathrm{N}=8)$ & $* *$ Optional teaching workshops and mini courses \\
& $* *$ Private meeting rooms \\
& $* *$ Better workspaces \\
& Help with designing rubrics \\
& Team teaching during first year \\
& $* *$ Mentorship for faculty in teaching and research \\
New faculty $(\mathrm{N}=4)$ & More access to TAs \\
& Peer observations
\end{tabular}

** Denotes at least 75\% agreement among new instructors within the category

The final themes outlined in table 3 above illustrate broader level challenges experienced by new instructors during their first year at the school. New part-time instructors stated that they did not feel very connected or received in the school, which left them wondering about the overall sense of community at the school. Additionally, new part-time instructors felt as though teaching was not valued at the same level as research focused activities. Finally, new part-time instructors found it difficult to work from the school or meet with students in privacy, because the spaces provided to them were not kept up with technology, offered limited work space, and offered no privacy for meeting with students about private or confidential information. Some new instructors also stated that they did not feel supported by the administration during 
challenging situations with students over grades, ethics, and unverified accommodations. Finally, some new instructors found parking to be a major barrier for part-time instructors because of the cost and limited locations available to part-time instructors.

Similar to part-time instructors, doctoral students stated that workspace was an issue due to privacy concerns in relation to student meetings. Additionally, doctoral students wanted more training and capacity building focus by the school as it related to teaching. While most doctoral students received training and mentorship in research, very few doctoral students received courses, workshops, trainings, and resources specific to teaching pedagogy, methods, and curriculum design. Doctoral students also expressed a desire to team teach in their first year to help strengthen their capacity to teach in the classroom.

The major theme identified from data collected from new faculty participants of TEAM was the need and desire for ongoing mentorship and support in research and teaching. While new faculty who participated in TEAM appreciated the support in teaching, faculty expressed a desire to also have support in research, preferably from a tenured faculty member with similar research and teaching interests. Similar to doctoral students, faculty instructors felt like team teaching in the first year with a mentor would be beneficial to them as they learned the curriculum and culture of the school, while also reducing workload stress the first year. New faculty also stated that teaching assistants would be extremely helpful in the classroom during the first year.

\section{Implications}

Through the piloting of the TEAM program a great deal of insights about the mentorship and support needs of new instructors was acquired, which will be used to inform the structure and process of the program in the future. A part-time instructor supported by a proactive associate dean developed the TEAM program at a grassroots level. However, the program took very few resources to support over three years (less than \$6000). One of the biggest takeaways from TEAM is that doing almost anything to support new instructors and to highlight the importance of teaching and community can lead to positive gains. New instructors often remarked that other instructors they met and spoke with stated that before TEAM, new instructors just received a master syllabus and maybe an email to a professor who previously taught the course during their first-semester teaching. As a result of TEAM, new instructors felt increasingly supported by the school, part-time instructors were retained at higher rates, and fewer student conflicts with instructors rose to the level of administrative action (Brady, 2015). An additional implication taken from TEAM is how important mentorship is to new instructors. While some readers may critique whether or not TEAM fits their definition of mentorship, one of the main objectives of the TEAM program was to foster supportive relationships among new instructors, as well as to promote relationships with experienced faculty and instructors at the school. While the TEAM program struggled with connecting new instructors to experienced faculty for ongoing support after the first year, it did open dialogue amongst faculty and administration about the importance of mentorship and teaching at an RI institution. Despite teaching being considered equally alongside research at the school from a tenure and promotion perspective, many faculty prioritized research and grant writing over teaching. Additionally, given the rising percentage of courses taught by part-time instructors, it raises the question about how well RI institutions are supporting educators in the classroom. Additionally, by not supporting instructors in the classroom, do some RI institutions unknowingly cost students a high-quality education? Finally, in relation to doctoral students, given that almost all of them will at some point find themselves

Journal of the Scholarship of Teaching and Learning, Vol. 18, No. 2, June 2018. josotl.indiana.edu 
in an employment position where teaching is a core responsibility, how well are institutions, especially outside the education/higher education field, preparing students for success in the classroom? Finally, while TEAM attempted to attain faculty buy-in and participation in the program in order to cultivate a culture of mentorship for teaching in the school, the program was not highly successful in doing so, which leaves the question: how do RI schools/institutions cultivate mentorship in relation to teaching?

\section{Limitations}

The TEAM pilot program demonstrated excellent beginning level results indicating that providing support and mentorship to new instructors was helpful and beneficial in the first year. While the beginning results of TEAM are promising, there were several limitations to the program and study. First, the sample size of 20 TEAM participants is small, and the results must be taken with caution. Additionally, while the evaluation for TEAM included all participants that utilized some portion of the program, instructors participated at various levels, making it difficult to ascertain what aspects of the program mattered most. Additionally, while all participants in the program participated in some check-in meetings and reflection sessions during their first year, not all new instructors attended all sessions, which could further bias perspectives about the program and overall experience at the school. Finally, the data shared in this paper does not illustrate whether or not the TEAM program improved the teaching of new instructors in the school through providing mentorship and support, but instead illustrates what aspects of the program were most beneficial to new instructors, how the program benefited them, and what additional needs and challenges were experienced by new instructors that the program may seek to address in the future.

\section{Conclusion}

While supporting the teaching of instructors, faculty members, and doctoral students seem like an intuitive part of the mission of institutions of higher education, the literature suggests otherwise, especially when it comes to supporting teaching at RI institutions. While most schools state that they value teaching, very few institutions and schools provide mentorship supports and resources to new instructors, especially part-time instructors, which is a major reason for creating TEAM. The TEAM program demonstrated that even the most basic semi-formal mentorship program could lead to positive gains among new instructors and be useful for identifying the needs of new instructors. While TEAM was considered a success by those involved, it also raised questions about the sustainability and buy-in of teaching specific mentorship programs among faculty, administration, and institutions. Finally, while TEAM did not seek to separate out adjuncts or doctoral students from new faculty members, the data indicated that there were some different mentorship needs among the various categories of new instructors, which must be closely considered before embarking on developing a mentorship program.

Journal of the Scholarship of Teaching and Learning, Vol. 18, No. 2, June 2018.

josotl.indiana.edu 


\section{References}

American Association of University Professors (2015). Background facts on contingent faculty. Retrieved from: https://www.aaup.org/issues/contingency/background-facts

Bazeley, P. (2009). Analyzing qualitative data: More than identifying themes. Malaysian Journal of Qualitative Research, 6, 6-22. Retrieved from:

https://www.researchgate.net/profile/Pat_Bazeley/publication/237458922_Analysing_qualitative _data_More_than_'identifying_themes'/links/581881f608ae50812f5d9f71.pdf

Boyle, P., \& Boice, B. (1998). Systematic mentoring for new faculty teachers and graduate assistants. Innovative Higher Education, 22, 157-179. Retrieved from:

http://link.springer.com/article/10.1023/A:1025183225886

Brady, S.R., \& Spencer, M. (2015) Teaching Excellence and Academic Mentorship Program Evaluation Report. Ann Arbor, MI: University of Michigan School of Social Work.

Cameron, S.W. \& Blackburn, R.T. (1981). Sponsorship and academic career success. Journal of Higher Education, 52, 369-377. Retrieved from: http://www.jstor.org/stable/1981284

Cox, M.D. (2004). Introduction to faculty learning communities. New directions for teaching and learning. 97, 5-23. https://doi.org/10.1002/tl.129

Fagan-Wilen, R., Springer, D.W., Ambrosino, B., \& White, B.W. (2006). The support of adjunct faculty: An academic imperative. Social Work Education, 25, 39-51.

https://doi.org/10.1080/02615470500477870

Friedlander, J. (1980). Instructional practices of part-time faculty. New Directions for Community Colleges, 30, 27-36. https://doi.org/10.1002/cc.36819803006

Freire, P. (1970). Pedagogy of the oppressed, trans.” Myra Bergman Ramos. New York: Continuum.

Gaia, A.C., Corts, D.P., Tatum, H.E., \& Allen, J. (2010). The GTA mentoring program: An interdisciplinary approach to developing future faculty as teacher-scholars. College Teaching, 51, 37-41. https://doi.org/10.1080/87567550309596413

Giroux, H.A. (2009). Education and the crisis of youth: Schooling and the promise of democracy. The Educational Forum, 73, 8-18. https://doi.org/10.1080/00131720802539523

Gonzalez, C. (2001). Undergraduate research, graduate mentoring, and the university's mission. Science, 293, 1624-1626. Doi:10.1126/science.1062714

Gross, E., \& Stovall, R. (1994). Valencia community college faculty academy: Preparing new faculty for tenure. Paper presented at the Annual National Institute for Staff and Organizational Development Conference, Austin, TX. Retrieved from: 
https://eric.ed.gov/?q=Addition\&ff1=subCommunity+Colleges\&ff2=subProgram+Development $\underline{\text { \&id=ED381213 }}$

Hénard, F., \& Roseveare, D. (2012). Fostering quality teaching in higher education: Policies and Practices. An IMHE Guide for Higher Education Institutions, 7-11. Retrieved from: https://www.oecd.org/education/imhe/QT\%20policies\%20and\%20practices.pdf

Hudson, P., Hudson, S., Gray, B., \& Bloxham, R. (2013). Learning about being effective mentors: professional learning communities and mentoring. Procedia-Social and Behavioral Sciences, 93, 1291-1300. http://doi.org/10.1016/j.sbspro.2013.10.031

Kalish, A. (1997). Learning to profess: The enculturation of new faculty members in English. Bloomington, IN: Indiana University Press.

Klein, W.C., Weisman, D., \& Smith, T.E. (1996). The use of adjunct faculty: An exploratory study of eight social work programs. Journal of Social Work Education, 32, 253-263. Retrieved from: http://www.tandfonline.com/doi/abs/10.1080/10437797.1996.10778456

Lange, E.A. (2004). Transformative and restorative learning: A vital dialectic for sustainable societies. Adult Education Quarterly, 54, 121-139. doi:10.1177/0741713603260276

Luna, G., \& Cullen, D.L. (1995). Empowering the faculty: Mentoring redirected and renewed. Washington D.C.: George Washington University Graduate School of Education and Human Development. Retrieved from: https://eric.ed.gov/?id=ED399889

Popper, A.N. (2007). Mentoring of junior faculty: A guide for faculty members (and mentees) in the College of Chemical and Life Sciences. College Park, MD: College of Chemical and Life Science. Retrieved from: https://pdc-svpaap1.umd.edu/faculty/documents/MentoringGuide.pdf

Richardson, R.C. (1992). The associate program: Teaching support for adjunct faculty. Community College Review, 20, 29-34. Retrieved from: http://eric.ed.gov/?id=EJ454858

Sands, R.G., Parson, A., \& Duane, J. (1991). Faculty mentoring faculty in a public university. The Journal of Higher Education, 62, 174-193. Retrieved from http://www.jstor.org/stable/1982144

Savage, H.E., Karp, R.S., \& Logue, R. (2004). Faculty mentorship at colleges and universities. College Teaching, 52, 21-24. Retrieved from http://dx.doi.org/10.3200/CTCH.52.1.21-24

Schonwetter, D. \& Nazarko, O. (2009). Investing in our next generation: overview of short courses, and teaching and mentoring programs for newly-hired faculty in Canadian universities (part 2). The Journal of Faculty Development, 23, 54-63. Retrieved from: http://www.ingentaconnect.com/content/nfp/jfd/2009/00000023/00000001/art00007 
Simon, C.E., Bowles, D.D., King, S.W., \& Roff, L.L. (2004). Mentoring in the careers of African American women in social work education. Affilia, 19, 134-145. doi:10.1177/0886109903262765

Sowers-Hoag, K.M., \& Harrison, D.F. (1991). Women in social work education: Progress or promise. Journal of Social Work Education, 27, 320-328. doi:10.1080/10437797.1991.10672204

St. Claire, K.L. (1994). Faculty-to-faculty mentorship in the community college: An instructional component of faculty development. Community College Review, 22, 23-37. doi:10.1177/009155219402200304

Stringer, E.T. (2014). Action research (4th edition). Thousand Oaks, CA: Sage Publications. Strauss, A., \& Corbin, J. (1998). Basics of qualitative research. Thousand Oaks, CA: Sage. Thomas, R. (2005). Exemplary junior faculty mentoring programs. Fairfield, IA: Walton Family Foundation.

Wasserstein, A.G., Quistberg, D.A., \& Shea, J.A. (2007). Mentoring at the University of Pennsylvania: Results of a faculty survey. Journal of General Internal Medicine, 22, 210-214. doi: 10.1007/s11606-006-0051-X

Wilson, P.P., Valentine, D., \& Periera, A. (2002). Perceptions of new social work faculty about mentoring experiences. Journal of Social Work Education, 38, 317-332.

https://doi.org/10.1080/10437797.2002.10779100 